\title{
Insulin Blocks Glutamate-Induced Neurotoxicity in Differentiated SH-SY5Y Neuronal Cells
}

\author{
Madhavan Nampoothiri, Neetinkumar D. Reddy, Jessy John, Nitesh Kumar, \\ Gopalan Kutty Nampurath, and Mallikarjuna Rao Chamallamudi
}

Department of Pharmacology, Manipal College of Pharmaceutical Sciences, Manipal University, Manipal, Karnataka 576104, India

Correspondence should be addressed to Mallikarjuna Rao Chamallamudi; mallikin123@gmail.com

Received 27 February 2014; Revised 4 May 2014; Accepted 26 May 2014; Published 15 June 2014

Academic Editor: Antonio Pisani

Copyright (c) 2014 Madhavan Nampoothiri et al. This is an open access article distributed under the Creative Commons Attribution License, which permits unrestricted use, distribution, and reproduction in any medium, provided the original work is properly cited.

Insulin is a cytokine which promotes cell growth. Recently, a few published reports on insulin in different cell lines support the antiapoptotic effect of insulin. But the reports fail to explain the role of insulin in modulating glutamate-mediated neuronal cell death through excitotoxicity. Thus, we examined the neuroprotective effect of insulin on glutamate-induced toxicity on differentiated SH-SY5Y neuronal cells. Changes in cell viability were measured by 3-(4,5-dimethylthiazol-2-yl)-2,5-diphenyltetrazolium bromide (MTT) based assay, while apoptotic damage was detected by acridine orange/ethidium bromide and Hoechst staining. Intracellular reactive oxygen species (ROS) accumulation and morphological alterations were also measured. Treatment with glutamate induced apoptosis, elevated ROS levels and caused damage to neurons. Insulin was able to attenuate the glutamateinduced excitotoxic damage to neuronal cells.

\section{Introduction}

Insulin is known for its action on peripheral target tissues such as liver, muscle, and adipose tissue through insulin receptors, regulating glucose uptake and utilisation, glycogen synthesis, phosphorylation or dephosphorylation of enzymes, and modulating cellular proliferation. In the brain, the presence of insulin receptor was identified years back $[1,2]$, but the receptor function in the CNS is still a mystery. Compared to glial cells, insulin receptors are present more in neurons [2] and are concentrated at the postsynaptic density [3]. Recent studies suggest the neurophysiological role of insulin in learning and memory $[4,5]$, cognition [6], and regulation of food intake [7]. The neurotrophic effects of insulin include maintenance of synaptic plasticity $[8,9]$ and differentiation and stimulation of neurite outgrowth [10] and circuit function [11].

Glutamate is a major excitatory neurotransmitter, widely distributed in the CNS. This excitatory aminoacid, through its action on glutamate receptors, modulates several functions of neurons including synaptic plasticity and organisation, long-term potentiation, and excitotoxicity. However, how insulin receptor signalling affects $\alpha$-amino-3-hydroxy5-methylisoxazole-4-propionic acid (AMPA) and $\mathrm{N}$-methyl$\mathrm{D}$-aspartate (NMDA) receptor-mediated transmission and glutamate-mediated excitotoxicity has not been explored.

Reactive oxygen species (ROS) plays a crucial role in the pathophysiology of neurodegenerative disorders (Alzheimer's disease) and metabolic disorders (diabetes mellitus) $[12,13]$. Further, ROS interacts with insulin receptor tyrosine phosphorylation, disrupting insulin signalling and affecting phosphatidyl inositol 3-kinase (PI3K) activation and insulin receptor substrate (IRS) phosphorylation [14, 15].

Insulin, after its entry into the CNS by crossing the blood brain barrier, binds to the insulin receptors located in hippocampus, cerebral cortex, cerebellum, and hypothalamus and activates intrinsic tyrosine kinase function. This triggers the subsequent signal transduction pathways. Recently, increasing body of evidence suggests the involvement of aberrant insulin receptor signalling in neurodegenerative disorders like Alzheimer's and Parkinson's disease [16, 17].

However, evidence supporting the role of insulin as a survival factor in the neuronal cells which express insulin receptors is scarce. Hence, we aimed to find out whether 
insulin protects neuronal cells from glutamate-induced excitotoxicity and if so whether antiapoptotic effect of insulin is mediated through oxidative stress pathway in SH-SY5Y human neuronal cells expressing insulin receptors.

\section{Materials and Methods}

2.1. Materials. Human recombinant insulin, acridine orange, ethidium bromide, all-trans retinoic acid (RA), dichlorofluorescein diacetate (DCFDH), 5,5' -dithiobis-(2-nitrobenzoic acid) [DTNB], Ham's F-12, Hoechst 33342, Eagle's minimum essential medium (MEM), and trypan blue were purchased from Sigma-Aldrich, USA. 3-(4,5-Dimethylthiazol-2-yl)-2,5diphenyl-tetrazolium bromide, disodium hydrogen phosphate dihydrate, monosodium glutamate monohydrate, and fetal bovine serum were procured from HiMedia Laboratories, India.

2.2. Cell Culture. SH-SY5Y, neuroblastoma cell line used in this study, was obtained from the National Centre for Cell Sciences (NCCS), Pune, India. The growth medium used was 1:1 mixture of Eagle's minimum essential medium with nonessential amino acids and Ham's F-12 medium supplemented with $10 \%$ fetal bovine serum (FBS) and gentamicin $(20 \mu \mathrm{g} / \mathrm{mL})$. The cells were maintained at $37^{\circ} \mathrm{C}$ in a $\mathrm{CO}_{2}$ incubator in a humidified atmosphere of $95 \%$ air and $5 \% \mathrm{CO}_{2}$.

\subsection{Induction of Neurotoxicity in Undifferentiated and Dif-} ferentiated SH-SY5Y Cell Line Using Glutamate. Twenty four hours after seeding, 5\% RA $(10 \mu \mathrm{M})$ was added to induce differentiation. Every two days, the medium was replaced with fresh medium containing RA $(10 \mu \mathrm{M})[18]$. On day 6, to investigate the excitotoxicity of L-glutamate, both undifferentiated and differentiated cells were treated with different concentrations of L-glutamate ranging from 5 to $80 \mathrm{mM}$ [19] and then $20 \mathrm{mM}$ was used for further studies as it produced a significant toxicity of around 35\% cell death in differentiated cells.

2.4. Cell Viability by MTT Assay [20]. 3-(4,5-Dimethylthiazol-2-yl)-2,5-diphenyl-tetrazolium bromide (MTT) assay was used to determine cell viability. Briefly, differentiated cells in 96-well culture plate were incubated with different concentrations of insulin $(0.01,0.1,1$, and $10 \mu \mathrm{M})$ and then exposed to $20 \mathrm{mM}$ glutamate. After 48 hours of incubation, $30 \mu \mathrm{L}(4 \mathrm{mg} / \mathrm{mL})$ of MTT reagent was added to each well followed by DMSO $(100 \mu \mathrm{L})$. The optical density was measured at $540 \mathrm{~nm}$ using a microplate reader (BioTek instruments, USA). The absorbance of the control group was considered as $100 \%$ of the cell viability. Percentage cell viability in each group was calculated.

2.5. Detection of Apoptotic Cells with Acridine Orange/Ethidium Bromide $(A O / E B)$ and Hoechst Staining. The cells were stained with fluorescent DNA binding dyes AO/EB and Hoechst 33342. In brief, differentiated cells were incubated with glutamate $(20 \mathrm{mM})$ alone and with different concentrations of insulin prior to glutamate exposure. After 48 hours of incubation, the medium containing drug was removed. The plate was washed and dried and $200 \mu \mathrm{L}$ of $\mathrm{AO} / \mathrm{EB}$ reagent or Hoechst reagent was added to each well and incubated at $37^{\circ} \mathrm{C}$ for 10 minutes and observed under Nikon eclipse TS100 inverted microscope using fluorescence filters. An excitation wavelength of $460 \mathrm{~nm}$ and an emission maximum of $650 \mathrm{~nm}$ were used in $\mathrm{AO} / \mathrm{EB}$ staining and, in Hoechst staining, $360 \mathrm{~nm}$ and $460 \mathrm{~nm}$ were used as excitation and emission wavelength, respectively. Three hundred cells were observed and the number of cells with apoptotic morphology appearing as condensed or fragmented nuclei was counted and expressed as percentage [21]. Apoptotic and necrotic cells were identified based on the staining pattern described by Ribble et al., 2005 [21]. Live cells were observed with normal green nuclei, early apoptotic cells with bright green nuclei with condensed or fragmented chromatin, late apoptotic cells with condensed and fragmented orange colored chromatin, and necrotic cells with structurally normal orange nuclei.

2.6. Intracellular Reactive Oxygen Species (ROS) Assay [22]. The differentiated cells were incubated with different concentrations of insulin $(0.01,0.1,1$, and $10 \mu \mathrm{M})$ and then exposed to $20 \mathrm{mM}$ glutamate. After 48 hours of incubation with insulin at different concentrations, the cell culture supernatants were discarded and replaced with $100 \mu \mathrm{L}$ of DCFDA $(100 \mu \mathrm{M})$. Following 1-hour incubation, the wells were washed with sterile $\mathrm{HBSS}$ at $37^{\circ} \mathrm{C}$. HBSS $(100 \mu \mathrm{L})$ was then added to each well and the fluorescence intensity was measured using a fluorescence microplate reader at an excitation wavelength of $488 \mathrm{~nm}$ and emission wavelength of $525 \mathrm{~nm}$. The ROS level was calculated with respect to normal control.

2.7. Study of Morphological Alterations and Estimation of Neurite Length. After 48 hours of incubation of differentiated SH-SY5Y cells with treatment, cells were viewed using an inverted microscope (Nikon) under 40X objective. These images were then compared to assess the effect of various treatments on the morphology of cells. For estimation of neurite length, approximately 100 images were acquired randomly from each well by scanning the wells from left to right and top to bottom. These images were then extracted to grey scale and neurite lengths were traced and measured using the public domain NIH Image J Software supplemented with Neuron J plug-in [23]. Length was defined as the straight-line distance from the tip of the neurite to the junction between the cell body and neurite base. The length $(\mu \mathrm{m})$ of neurite for each treatment was calculated.

2.8. Statistical Analysis. Data were statistically analysed using GraphPad Prism 5.0 software. Values are expressed as mean \pm SEM of three tests in triplicate and statistical comparisons were made by one-way ANOVA followed by Tukey's multiple comparison test, where $P<0.05$ was considered statistically significant. 
TABLE 1: Effect of treatments on cell viability in differentiated SHSY5Y cells.

\begin{tabular}{lc}
\hline Treatment & Percentage cell viability \\
\hline Control & $100.00 \pm 0.012$ \\
Insulin $(0.01 \mu \mathrm{M})$ & $110.66 \pm 7.2$ \\
Insulin $(0.1 \mu \mathrm{M})$ & $149.09 \pm 17.0$ \\
Insulin $(1 \mu \mathrm{M})$ & $165.83 \pm 10.0^{*}$ \\
Insulin $(10 \mu \mathrm{M})$ & $139.67 \pm 14.3$ \\
\hline
\end{tabular}

Values are expressed as mean \pm SEM of three tests in triplicate. Statistical analysis was done by using one-way ANOVA followed by Tukey's multiple comparison test. ${ }^{*} P<0.05$ compared to control group.

TABLE 2: Effect of treatments on cell viability in differentiated SHSY5Y cells in the presence of glutamate $(20 \mathrm{mM})$.

\begin{tabular}{lc}
\hline Treatment & Percentage cell viability \\
\hline Control & $100.00 \pm 0.012$ \\
Glutamate $(20 \mathrm{mM})$ & $65.80 \pm 1.316^{*}$ \\
Glutamate + insulin $(0.01 \mu \mathrm{M})$ & $108.01 \pm 1.8^{\# \#}$ \\
Glutamate + insulin $(0.1 \mu \mathrm{M})$ & $139.88 \pm 10.4^{\# \# \#}$ \\
Glutamate + insulin $(1 \mu \mathrm{M})$ & $132.89 \pm 9.5^{\# \# \#}$ \\
Glutamate + insulin $(10 \mu \mathrm{M})$ & $128.13 \pm 5.4^{\# \# \#}$ \\
\hline
\end{tabular}

Values are expressed as mean \pm SEM of three tests in triplicate. Statistical analysis was done by using one-way ANOVA followed by Tukey's multiple comparison test. ${ }^{*} P<0.05$ compared to control group. ${ }^{\# \#} P<0.01$ and ${ }^{\# \#} P$ $<0.001$ compared to glutamate alone.

\section{Results}

3.1. Effect of Glutamate on Cell Viability in SH-SY5Y Cells. In undifferentiated and differentiated cells, glutamate treatment resulted in a significant decrease in cell viability in a concentration-dependent manner (Figures 1(a) and 1(b)). After differentiation, MTT assay showed an increase in the number of viable cells compared to undifferentiated cells after exposure to glutamate, which indicates that RA differentiated cells $\left(\mathrm{CTC}_{50}\right.$ value $\left.70.36 \mathrm{mM}\right)$ are less susceptible to glutamate toxicity than undifferentiated cells. Treatment with glutamate $20 \mathrm{mM}$ produced about $35 \%$ cell death in differentiated cells and this concentration was used for further studies (Figure 1(b)).

\subsection{Effect of Insulin on Glutamate-Induced Viability Loss} in Differentiated SH-SY5Y Cells. Treatment with insulin increased the growth of SH-SY5Y cells compared to control cells. Maximum cell viability was observed at $1 \mu \mathrm{M}$ of insulin (Table 1). Cytotoxicity induced by glutamate treatment reduced the viability of cells to $65.80 \pm 1.316 \%$ (Table 2 ). Insulin pretreatment at all tested concentrations $(0.01 \mu \mathrm{M}-$ $10 \mu \mathrm{M})$ prevented the glutamate-induced cytotoxicity. Maximum protection was observed at $0.1 \mu \mathrm{M}$ of insulin pretreatment (Table 2).

\subsection{Effect of Treatments on Glutamate-Induced Apoptosis in SH-SY5Y Cells}

3.3.1. Acridine Orange/Ethidium Bromide (AO/EB) Staining. Control cells were found to have less than $10 \%$ of apoptotic cells $(6.50 \pm 2.50 \%)$. Treatment with glutamate at $20 \mathrm{mM}$
TABLE 3: Percentage of apoptotic cells in differentiated SH-SY5Y cells after treatment.

\begin{tabular}{lc}
\hline Treatment & Apoptotic cells $(\%$ of total) \\
\hline Control & $6.50 \pm 2.50$ \\
Glutamate $(20 \mathrm{mM})$ & $35.33 \pm 2.91^{* *}$ \\
Glutamate + insulin $(0.1 \mu \mathrm{M})$ & $11.67 \pm 3.71^{\# \#}$ \\
Glutamate + insulin $(1 \mu \mathrm{M})$ & $13.22 \pm 2.79^{\# \#}$
\end{tabular}

Values are expressed as mean \pm SEM of three tests in triplicate. Statistical analysis was done by using one-way ANOVA followed by Tukey's multiple comparison test. ${ }^{* *} P<0.01$ compared to control group. ${ }^{\# \#} P<0.01$ compared to glutamate group.

TABLE 4: Percentage of apoptotic cells in differentiated SH-SY5Y cells after treatment.

\begin{tabular}{lc}
\hline Treatment & Apoptotic cells $(\%$ of total) \\
\hline Control & $8.00 \pm 2.31$ \\
Glutamate $(20 \mathrm{mM})$ & $27.33 \pm 2.91^{* *}$ \\
Glutamate + insulin $(0.1 \mu \mathrm{M})$ & $13.00 \pm 2.00^{\#}$ \\
Glutamate + insulin $(1 \mu \mathrm{M})$ & $11.67 \pm 2.90^{\#}$
\end{tabular}

Values are expressed as mean \pm SEM of three tests in triplicate. Statistical analysis was done by using one-way ANOVA followed by Tukey's multiple comparison test. ${ }^{* *} P<0.01$ compared to control group. ${ }^{\sharp} P<0.05$ compared to glutamate group.

concentration significantly $(P<0.01)$ increased the apoptosis $(35.33 \pm 2.91 \%)$ compared to control cells. Pretreatment with insulin significantly $(P<0.01)$ prevented the morphonuclear changes induced by glutamate $(20 \mathrm{mM})$ in cells at both tested concentrations $(0.1 \mu \mathrm{M}$ and $1 \mu \mathrm{M})$ compared to glutamate alone (Figure 2 and Table 2).

3.3.2. Hoechst 33342 Staining. Hoechst 33342 staining also showed similar results to that of $\mathrm{AO} / \mathrm{EB}$ staining. Control cells were found to be healthy with less than $10 \%$ of apoptotic cells $(8.00 \pm 2.31 \%)$. Treatment with glutamate $(20 \mathrm{mM})$ increased the apoptosis $(27.33 \pm 2.91 \%)$ in cells significantly $(P<0.01)$ compared to control cells. Insulin pretreatment at both tested concentrations significantly prevented apoptosis induced by glutamate compared to glutamate alone (Figure 3 and Table 3).

3.4. Effect of Insulin on Glutamate-Induced Morphological Alterations in Neurite Length. RA treatment caused differentiation in SH-SY5Y control cells, as evidenced by a neurite length of $799.0 \pm 66.70 \mu \mathrm{m}$. In differentiated cells, glutamate treatment significantly $(P<0.01)$ decreased the neurite length $(190.1 \pm 12.83 \mu \mathrm{m})$ compared to control cells. Insulin pretreatment at both tested concentrations $(0.1 \mu \mathrm{M}$ and $1 \mu \mathrm{M})$ significantly minimised the glutamate-induced decrease in neurite length (Figure 4 and Tables 4 and 5).

3.5. Intracellular Reactive Oxygen Species (ROS) Assay in SH-SY5Y Cells. Glutamate treatment produced a twofold increase in the ROS formation in differentiated SH-SY5Y cells. Treatments with insulin at all tested concentrations significantly minimised the glutamate-induced ROS formation 


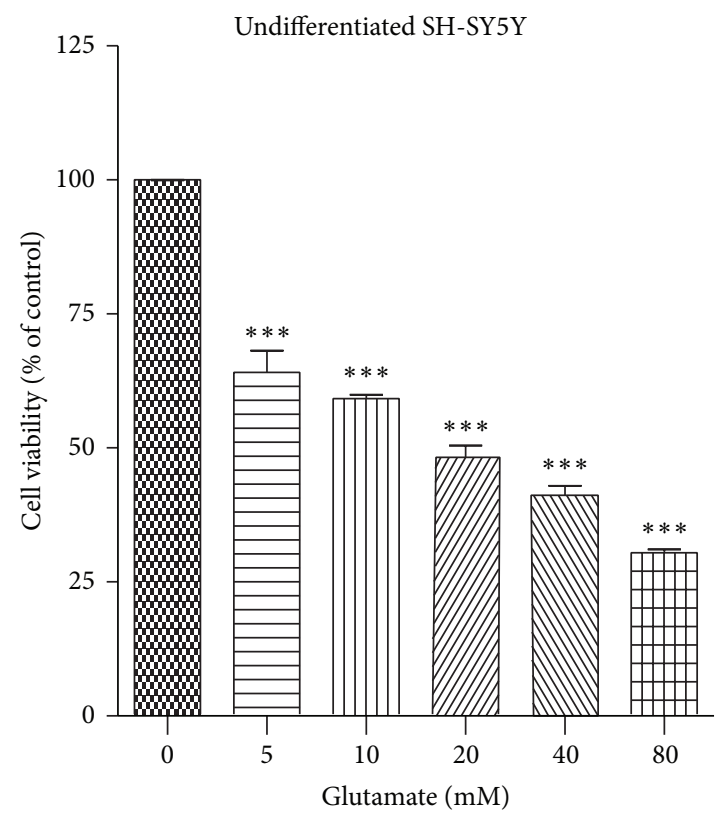

(a)

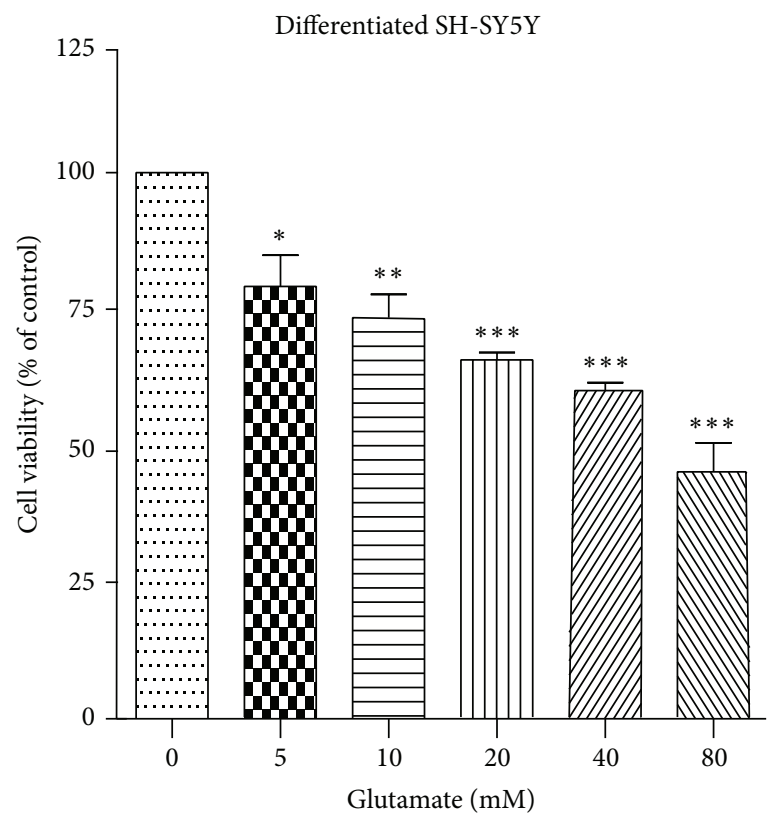

(b)

FIGURE 1: Effect of different concentrations of glutamate on cell viability in (a) undifferentiated SH-SY5Y cells and (b) differentiated SH-SY5Y cells. Values are expressed as mean \pm SEM of three tests in triplicate. Statistical analysis was done by using one-way ANOVA followed by Tukey's multiple comparison test. ${ }^{*} P<0.05,{ }^{* *} P<0.01$, and ${ }^{* * *} P<0.001$ compared to control group.

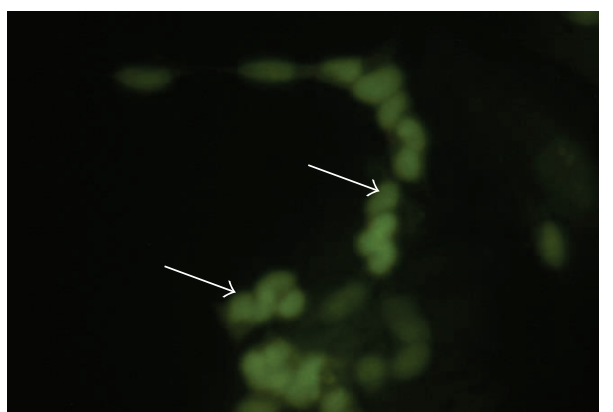

(a)

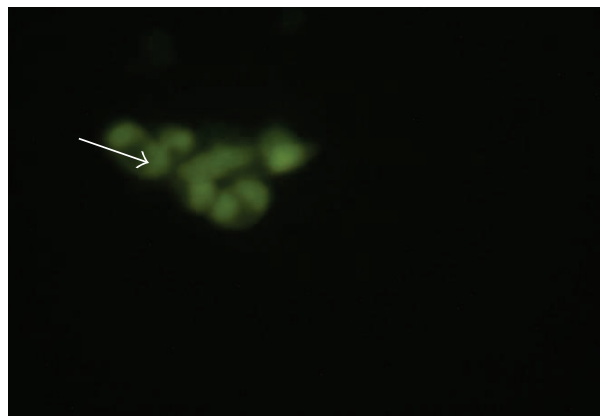

(c)

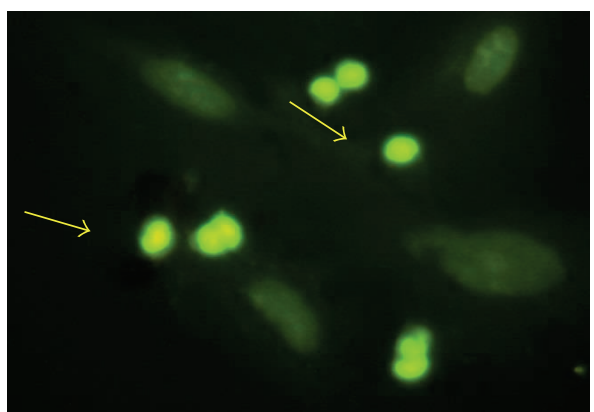

(b)

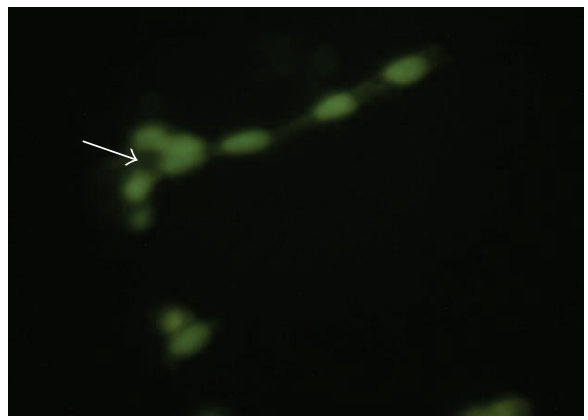

(d)

Figure 2: AO/EB staining in differentiated SH-SY5Y cells after treatment. (a) Control, (b) glutamate (20 mM), (c) glutamate (20 mM) + insulin $(0.1 \mu \mathrm{M})$, and $(\mathrm{d})$ glutamate $(20 \mathrm{mM})+$ insulin $(1 \mu \mathrm{M})$. White arrow: live cell; yellow arrow: apoptotic cell. 


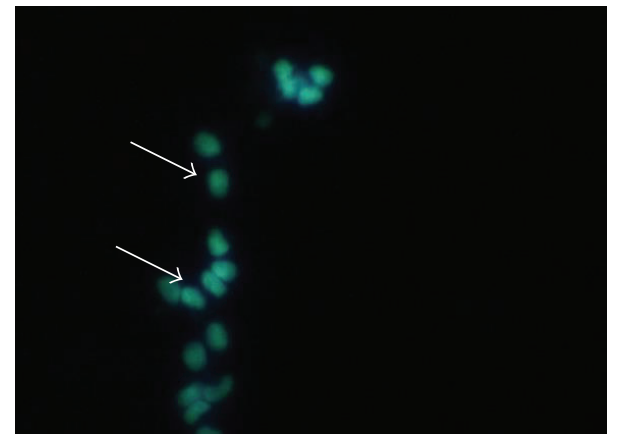

(a)

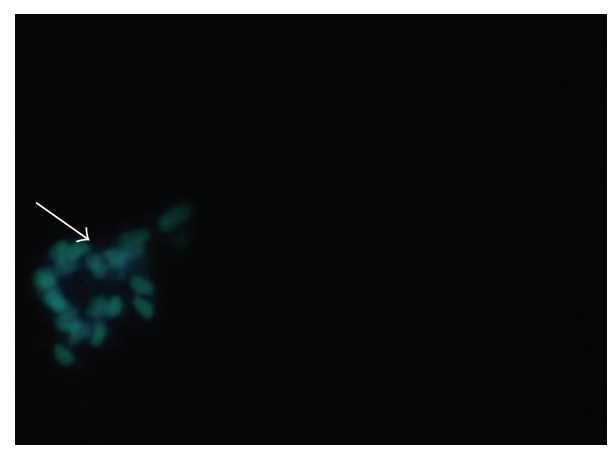

(c)

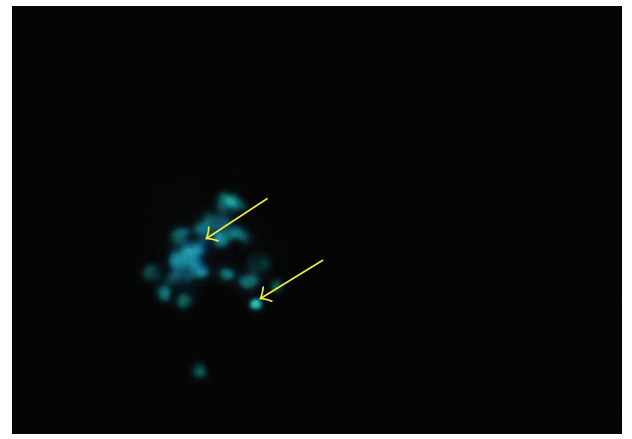

(b)

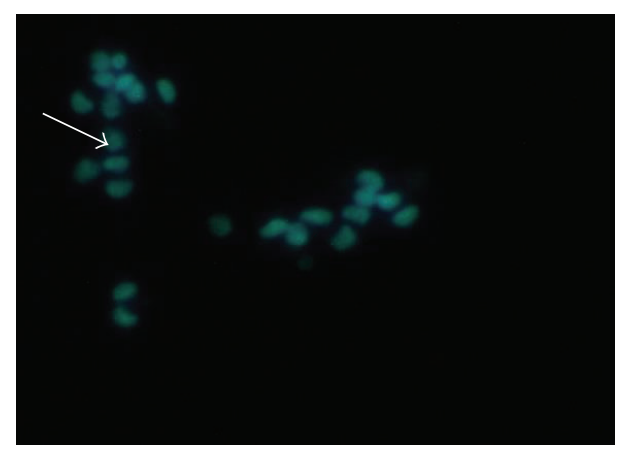

(d)

FIGURE 3: Hoechst staining in differentiated SH-SY5Y cells after treatment. (a) Control, (b) glutamate (20 mM), (c) glutamate (20 mM) + insulin $(0.1 \mu \mathrm{M})$, and $(\mathrm{d})$ glutamate $(20 \mathrm{mM})+$ insulin $(1 \mu \mathrm{M})$. White arrow: live cell; yellow arrow: apoptotic cell.

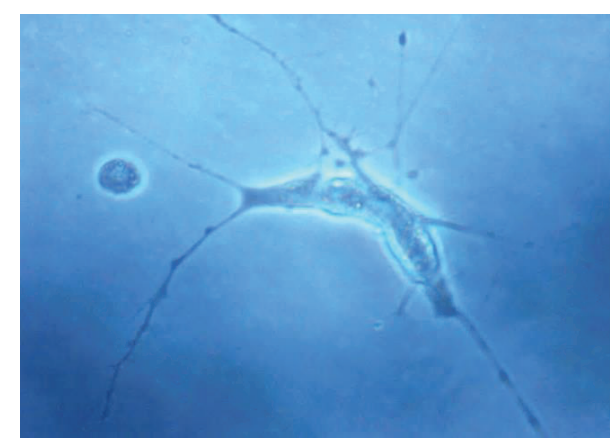

(a)

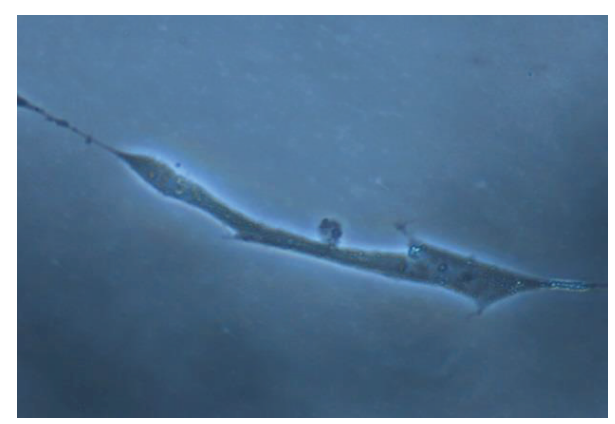

(c)

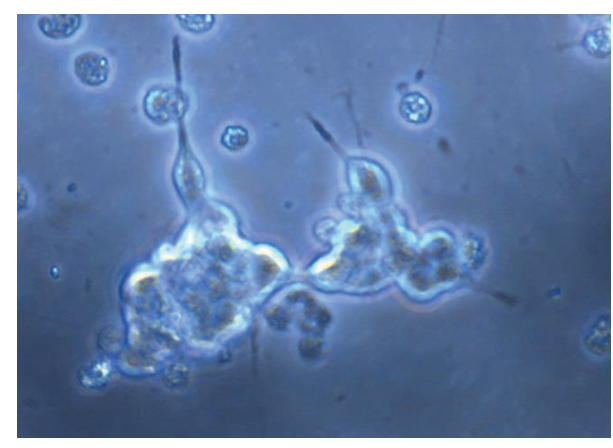

(b)

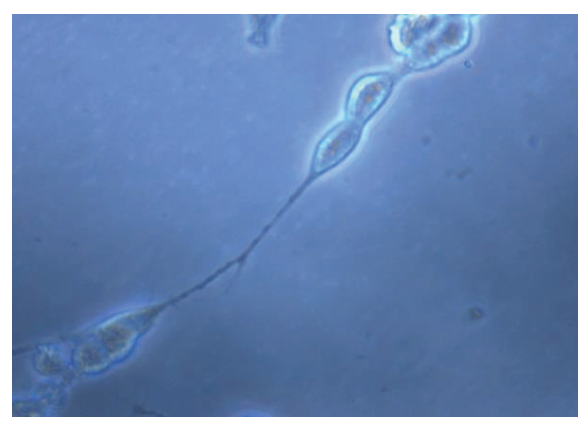

(d)

FiguRE 4: Effect of treatments on morphology of differentiated SH-SY5Y cells. (a) Control, (b) glutamate (20 mM), (c) glutamate + insulin $(0.1 \mu \mathrm{M})$, and $(\mathrm{d})$ glutamate + insulin $(1 \mu \mathrm{M})$. 
TABLE 5: Effect of treatments on length of neurites.

\begin{tabular}{lc}
\hline Treatment & Neurite length $(\mu \mathrm{m})$ \\
\hline Control & $799.0 \pm 66.70$ \\
Glutamate $(20 \mathrm{mM})$ & $190.1 \pm 12.83^{* *}$ \\
Glutamate + insulin $(0.1 \mu \mathrm{M})$ & $640.46 \pm 44.32^{\#}$ \\
Glutamate + insulin $(1 \mu \mathrm{M})$ & $552.22 \pm 22.90^{\# \#}$ \\
\hline
\end{tabular}

Values are expressed as mean \pm SEM of three tests in triplicate. Statistical analysis was done by using one-way ANOVA followed by Tukey's multiple comparison test. ${ }^{* * *} P<0.001$ compared to control group, ${ }^{\#} P<0.05$ compared to glutamate group, and ${ }^{\# \#} P<0.01$ compared to glutamate group.

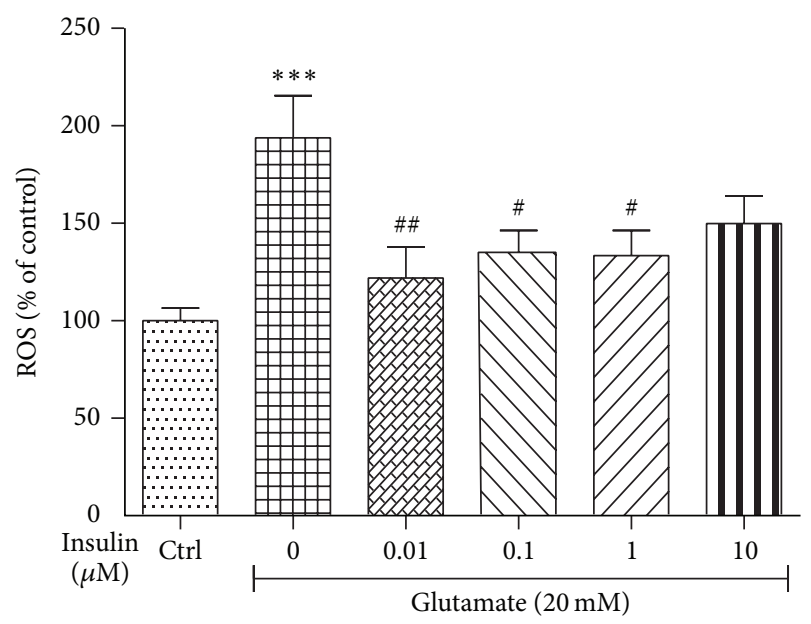

FIGURE 5: Effect of insulin pretreatment on the glutamate-induced ROS accumulation in differentiated SH-SY5Y cells. Values are expressed as mean \pm SEM of three tests in triplicate. Statistical analysis was done by using one-way ANOVA followed by Tukey's multiple comparison test. ${ }^{* * *} P<0.001$ compared to control group, ${ }^{\#} P<0.05$ compared to glutamate group, and ${ }^{\# \#} P<0.01$ compared to glutamate group.

in a dose-dependent manner. The maximum ROS inhibitory effect was seen at $0.01 \mu \mathrm{M}$ of insulin pretreatment (Figure 5).

\section{Discussion}

Due to sedentary lifestyle and increased life expectancy, the incidence of neurodegenerative disorders like Alzheimer's disease, Parkinson's disease, and so forth is increasing year by year. In neurodegenerative disorders, the major mechanisms responsible for neuronal cell death include excitotoxicity, oxidative stress, apoptosis, and protein ( $\alpha$-synuclein, $\beta$ amyloid) deposition [24-27]. In the present study, we evaluated the ability of insulin to antagonize the glutamateinduced excitotoxicity in differentiated SH-SY5Y cells. Further, we examined the antiapoptotic potential and ability of insulin to reduce oxidative stress.

Since the neuroblastoma cell lines like SH-SY5Y lack many of the features of mature neurons, differentiation is needed to induce neuron-like properties such as neurite outgrowth and morphological changes $[28,29]$. In the present study, retinoic acid $(10 \mu \mathrm{M})$ was used to induce differentiation.
Glutamate has several functions to perform in the CNS as an excitatory neurotransmitter. However, it is highly toxic to neurons due to its property to cause excitotoxicity to neuronal cells. Neuronal cell death results from increased calcium load and activation of proteases and generation of ROS and nitric oxide induced by activation of glutamate receptor stimulation [30]. Several environmental toxins like kainic acid and domoic acid that act as agonists on glutamate receptor have been shown to induce neurodegenerative conditions [31, 32]. Glutamate-induced cytotoxicity has been demonstrated in various neuronal cell lines $[19,33,34]$. In the present study, glutamate exposure at various concentrations resulted in significant toxicity in both differentiated and undifferentiated cells. But after differentiation, an increase in the cell viability was observed and it correlates well with the finding that RA-induced differentiation leads to upregulation of survival signalling and reduced susceptibility to neurotoxins [18, 35]. In the present study, treatment of SH-SY5Y cells with various concentrations of insulin alone did not produce any cytotoxicity to the cells, whereas insulin at all tested concentrations significantly prevented glutamate- $(20 \mathrm{mM})$ induced loss of cell viability. The maximum cell viability was observed at $0.1 \mu \mathrm{M}$; thereafter, cell viability decreased with increase in dose, indicating the dose-dependent antagonizing effect of insulin against glutamate. Evaluation of apoptotic cells by Hoechst 33342 and AO/EB staining reveals the antiapoptotic nature of insulin in neuronal cells. Further, insulin significantly reversed glutamate-induced damage to neurons as indicated by increased neurite length. Glutamateinduced cytotoxicity also involves the generation of reactive oxygen species $[36,37]$. In the present study, exposure of SHSY5Y cells to glutamate led to elevation in the level of reactive oxygen species. Treatment with insulin reversed glutamateinduced elevation in reactive oxygen species level.

In excitatory receptor trafficking, insulin causes the internalization of AMPA receptors, resulting in long-term depression of excitatory synaptic transmission crucial for the storage of information in the brain $[38,39]$. Further insulin stimulates the synthesis of PSD-95, a dendritic scaffolding protein that holds the cytoskeletal elements and receptors at synapses [40]. Modulation of NMDA-mediated synaptic transmission is also postulated [41]. Optimization of connections in brain circuits requires a mature synaptic connection at glutamatergic synapses. For this conversion of silent glutamatergic synapses into functional synapses is required $[42,43]$. This is attained through redistribution of AMPA receptor [16], which in turn mediates synaptic transmission through strengthening glutamatergic synapses. But the basis of AMPA transmission mediated through insulin receptor signalling still remains controversial and needs to be studied further.

The biological significance of ROS in neurodegeneration is well documented. The intracellular calcium overload due to glutamatergic receptor stimulation and oxidative stress may lead to caspase-3 activation resulting in cell death. Insulin reduced glutamate-triggered ROS production in our study, which may be due to the ability of insulin to suppress caspase3 activity [44]. The downstream cascades of insulin receptor, the PI3K/Akt/mTOR, and Ras/MAPK pathways, implicated 
for antiapoptotic action of insulin in peripheral tissues, may also play a major role in protecting SH-SY5Y cells from apoptosis due to oxidative stress in response to insulin.

\section{Conclusion}

Thus, the present study demonstrated the neuroprotective effect of insulin against glutamate-induced neurotoxicity in differentiated SH-SY5Y neuronal cells that express insulin receptor by multiple mechanisms involving reduction in glutamate-induced cell loss, prevention of apoptosis, and reducing the production of reactive oxygen species.

\section{Conflict of Interests}

The authors declare no conflict of interests.

\section{Acknowledgments}

The authors express their sincere thanks to the Manipal College of Pharmaceutical Sciences, Manipal, and Manipal University for having provided research facility and they also thank the Indian Council of Medical Research (IRIS no. 5/4-5/94/Neuro/2012-NCD-I) for financial assistance and the Department of Science and Technology (FIST-Scheme) for providing infrastructural support.

\section{References}

[1] J. Havrankova, J. Roth, and M. Brownstein, "Insulin receptors are widely distributed in the central nervous system of the rat," Nature, vol. 272, no. 5656, pp. 827-829, 1978.

[2] J. Unger, T. H. McNeill, R. T. Moxley III, M. White, A. Moss, and J. N. Livingston, "Distribution of insulin receptor-like immunoreactivity in the rat forebrain," Neuroscience, vol. 31, no. 1, pp. 143-157, 1989.

[3] M.-A. Abbott, D. G. Wells, and J. R. Fallon, “The insulin receptor tyrosine kinase substrate $\mathrm{p} 58 / 53$ and the insulin receptor are components of CNS synapses," The Journal of Neuroscience, vol. 19, no. 17, pp. 7300-7308, 1999.

[4] C. Benedict, M. Hallschmid, A. Hatke et al., "Intranasal insulin improves memory in humans," Psychoneuroendocrinology, vol. 29, no. 10, pp. 1326-1334, 2004.

[5] C. Benedict, M. Hallschmid, K. Schmitz et al., "Intranasal insulin improves memory in humans: superiority of insulin aspart," Neuropsychopharmacology, vol. 32, no. 1, pp. 239-243, 2007.

[6] M. A. Reger, G. S. Watson, P. S. Green et al., "Intranasal insulin improves cognition and modulates $\beta$-amyloid in early $\mathrm{AD}$," Neurology, vol. 70, no. 6, pp. 440-448, 2008.

[7] U. Stockhorst, D. de Fries, H.-J. Steingrueber, and W. A. Scherbaum, "Insulin and the CNS: effects on food intake, memory, and endocrine parameters and the role of intranasal insulin administration in humans," Physiology \& Behavior, vol. 83, no. 1, pp. 47-54, 2004.

[8] C.-C. Huang, J.-L. You, C.-C. Lee, and K.-S. Hsu, "Insulin induces a novel form of postsynaptic mossy fiber long-term depression in the hippocampus," Molecular and Cellular Neuroscience, vol. 24, no. 3, pp. 831-841, 2003.
[9] X.-H. Ma, P. Zhong, Z. Gu, J. Feng, and Z. Yan, "Muscarinic potentiation of GABAA receptor currents is gated by insulin signaling in the prefrontal cortex," The Journal of Neuroscience, vol. 23, no. 4, pp. 1159-1168, 2003.

[10] E. Recio-Pinto and D. N. Ishii, "Effects of insulin, insulin-like growth factor-II and nerve growth factor on neurite outgrowth in cultured human neuroblastoma cells," Brain Research, vol. 302, no. 2, pp. 323-334, 1984.

[11] S.-L. Chiu and H. T. Cline, "Insulin receptor signaling in the development of neuronal structure and function," Neural Development, vol. 5, no. 1, article 7, 2010.

[12] D. A. Butterfield, "Amyloid $\beta$-peptide [1-42]-assosiated free radical-induced oxidative stress and neurodegeneration in alzheimer's disease brain: mechanisms and consequences," Current Medicinal Chemistry, vol. 10, no. 24, pp. 2651-2659, 2003.

[13] A. C. Maritim, R. A. Sanders, and J. B. Watkins III, "Diabetes, oxidative stress, and antioxidants: a review," Journal of Biochemical and Molecular Toxicology, vol. 17, no. 1, pp. 24-38, 2003.

[14] A. Tirosh, R. Potashnik, N. Bashan, and A. Rudich, "Oxidative stress disrupts insulin-induced cellular redistribution of insulin receptor substrate-1 and phosphatidylinositol 3-kinase in 3T3L1 adipocytes: a putative cellular mechanism for impaired protein kinase B activation and GLUT4 translocation," The Journal of Biological Chemistry, vol. 274, no. 15, pp. 10595-10602, 1999.

[15] J. L. Evans, I. D. Goldfine, B. A. Maddux, and G. M. Grodsky, "Are oxidative stress-activated signaling pathways mediators of insulin resistance and $\beta$-cell dysfunction?" Diabetes, vol. 52, no. 1, pp. 1-8, 2003.

[16] W.-Q. Zhao, H. Chen, M. J. Quon, and D. L. Alkon, "Insulin and the insulin receptor in experimental models of learning and memory," European Journal of Pharmacology, vol. 490, no. 1-3, pp. 71-81, 2004.

[17] R. Agrawal, E. Tyagi, R. Shukla, and C. Nath, "A study of brain insulin receptors, AChE activity and oxidative stress in rat model of ICV STZ induced dementia," Neuropharmacology, vol. 56, no. 4, pp. 779-787, 2009.

[18] Y.-T. Cheung, W. K.-W. Lau, M.-S. Yu et al., "Effects of all-transretinoic acid on human SH-SY5Y neuroblastoma as in vitro model in neurotoxicity research," NeuroToxicology, vol. 30, no. 1, pp. 127-135, 2009.

[19] Z.-W. Sun, L. Zhang, S.-J. Zhu, W.-C. Chen, and B. Mei, "Excitotoxicity effects of glutamate on human neuroblastoma SH-SY5Y cells via oxidative damage," Neuroscience Bulletin, vol. 26, no. 1, pp. 8-16, 2010.

[20] D. Gerlier and N. Thomasset, "Use of MTT colorimetric assay to measure cell activation," Journal of Immunological Methods, vol. 94, no. 1-2, pp. 57-63, 1986.

[21] D. Ribble, N. B. Goldstein, D. A. Norris, and Y. G. Shellman, "A simple technique for quantifying apoptosis in 96-well plates," BMC Biotechnology, vol. 5, article 12, 2005.

[22] H. Wang and J. A. Joseph, "Quantifying cellular oxidative stress by dichlorofluorescein assay using microplate reader," Free Radical Biology \& Medicine, vol. 27, no. 5-6, pp. 612-616, 1999.

[23] E. Meijering, M. Jacob, J.-C. F. Sarria, P. Steiner, H. Hirling, and M. Unser, "Design and validation of a tool for neurite tracing and analysis in fluorescence microscopy images," Cytometry A, vol. 58, no. 2, pp. 167-176, 2004.

[24] Y. Liu, T. P. Wong, M. Aarts et al., "NMDA receptor subunits have differential roles in mediating excitotoxic neuronal death 
both in vitro and in vivo," The Journal of Neuroscience, vol. 27, no. 11, pp. 2846-2857, 2007.

[25] K. A. Khan, N. Kumar, P. G. Nayak et al., "Impact of caffeic acid on aluminium chloride-induced dementia in rats," Journal of Pharmacy and Pharmacology, vol. 65, no. 12, pp. 1745-1752, 2013.

[26] S. Fujioka, K. Ogaki, P. M. Tacik, R. J. Uitti, O. A. Ross, and Z. K. Wszolek, "Update on novel familial forms of Parkinson's disease and multiple system atrophy," Parkinsonism \& Related Disorders, vol. 20, supplement 1, pp. S29-S34, 2014.

[27] G. D. Rabinovici and W. J. Jagust, "Amyloid imaging in aging and dementia: testing the amyloid hypothesis in vivo," Behavioural Neurology, vol. 21, no. 1-2, pp. 117-128, 2009.

[28] S. H. Hashemi, J.-Y. Li, H. Ahlman, and A. Dahlström, "SSR2(a) receptor expression and adrenergic/cholinergic characteristics in differentiated SH-SY5Y cells," Neurochemical Research, vol. 28, no. 3-4, pp. 449-460, 2003.

[29] P. Tosetti, V. Taglietti, and M. Toselli, "Functional changes in potassium conductances of the human neuroblastoma cell line SH-SY5Y during in vitro differentiation," Journal of Neurophysiology, vol. 79, no. 2, pp. 648-658, 1998.

[30] X.-X. Dong, Y. Wang, and Z.-H. Qin, "Molecular mechanisms of excitotoxicity and their relevance to pathogenesis of neurodegenerative diseases," Acta Pharmacologica Sinica, vol. 30, no. 4, pp. 379-387, 2009.

[31] Q. Wang, S. Yu, A. Simonyi, G. Y. Sun, and A. Y. Sun, "Kainic acid-mediated excitotoxicity as a model for neurodegeneration," Molecular Neurobiology, vol. 31, no. 1-3, pp. 3-16, 2005.

[32] A. Chandrasekaran, G. Ponnambalam, and C. Kaur, "Domoic acid-induced neurotoxicity in the hippocampus of adult rats," Neurotoxicity Research, vol. 6, no. 2, pp. 105-117, 2004.

[33] C. Behl, M. Widmann, T. Trapp, and F. Holsboer, "17- $\beta$ estradiol protects neurons from oxidative stress-induced cell death in vitro," Biochemical and Biophysical Research Communications, vol. 216, no. 2, pp. 473-482, 1995.

[34] P. Froissard and D. Duval, "Cytotoxic effects of glutamic acid on PC12 cells," Neurochemistry International, vol. 24, no. 5, pp. 485-493, 1994.

[35] J.-H. Lee and K.-T. Kim, "Induction of cyclin-dependent kinase 5 and its activator p35 through the extracellular-signalregulated kinase and protein kinase a pathways during retinoicacid mediated neuronal differentiation in human neuroblastoma SK-N-BE(2)C cells," Journal of Neurochemistry, vol. 91, no. 3, pp. 634-647, 2004.

[36] P. G. Gunasekar, A. G. Kanthasamy, J. L. Borowitz, and G. E. Isom, "NMDA receptor activation produces concurrent generation of nitric oxide and reactive oxygen species: implication for cell death," Journal of Neurochemistry, vol. 65, no. 5, pp. 20162021, 1995.

[37] I. J. Reynolds and T. G. Hastings, "Glutamate induces the production of reactive oxygen species in cultured forebrain neurons following NMDA receptor activation," The Journal of Neuroscience, vol. 15, no. 5, pp. 3318-3327, 1995.

[38] H.-Y. Man, J. W. Lin, W. H. Ju et al., "Regulation of AMPA receptor-mediated synaptic transmission by clathrindependent receptor internalization," Neuron, vol. 25, no. 3, pp. 649-662, 2000.

[39] Y. T. Wang and D. J. Linden, "Expression of cerebellar long-term depression requires postsynaptic clathrin-mediated endocytosis," Neuron, vol. 25, no. 3, pp. 635-647, 2000.
[40] C.-C. Lee, C.-C. Huang, M.-Y. Wu, and K.-S. Hsu, "Insulin stimulates postsynaptic density- 95 protein translation via the phosphoinositide 3-kinase-Akt-mammalian target of rapamycin signaling pathway," The Journal of Biological Chemistry, vol. 280, no. 18, pp. 18543-18550, 2005.

[41] V. A. Skeberdis, J.-Y. Lan, X. Zheng, R. S. Zukin, and M. V. L. Bennett, "Insulin promotes rapid delivery of N-methyl-Daspartate receptors to the cell surface by exocytosis," Proceedings of the National Academy of Sciences of the United States of America, vol. 98, no. 6, pp. 3561-3566, 2001.

[42] G.-Y. Wu, R. Malinow, and H. T. Cline, "Maturation of a central glutamatergic synapse," Science, vol. 274, no. 5289, pp. 972-976, 1996.

[43] J. J. Renger, C. Egles, and G. Liu, "A developmental switch in neurotransmitter flux enhances synaptic efficacy by affecting AMPA receptor activation," Neuron, vol. 29, no. 2, pp. 469-484, 2001.

[44] S. Kang, J. Song, H. Kang, S. Kim, Y. Lee, and D. Park, "Insulin can block apoptosis by decreasing oxidative stress via phosphatidylinositol 3-kinase- and extracellular signal-regulated protein kinase-dependent signaling pathways in HepG2 cells," European Journal of Endocrinology, vol. 148, no. 1, pp. 147-155, 2003. 


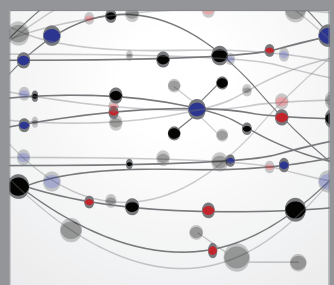

The Scientific World Journal
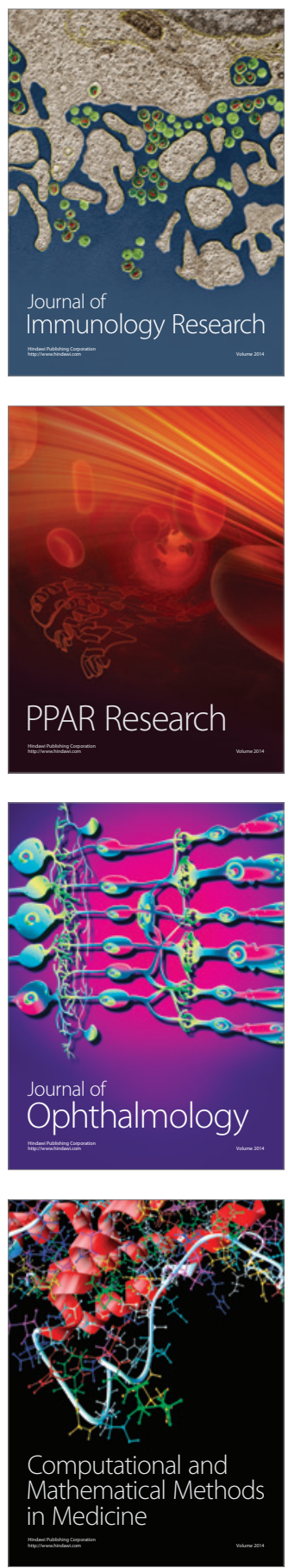

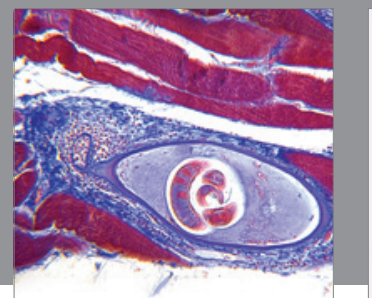

Gastroenterology

Research and Practice
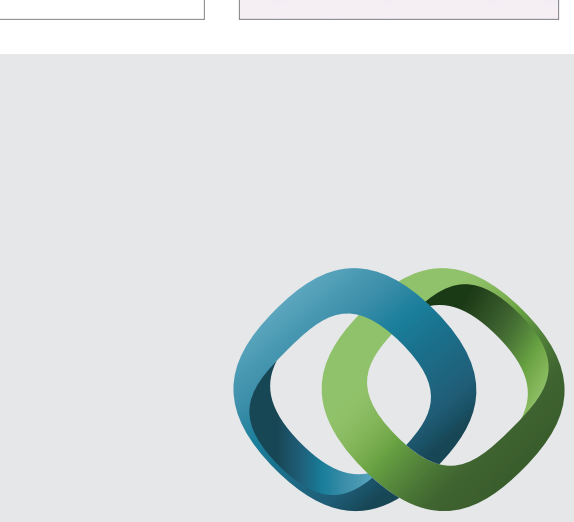

\section{Hindawi}

Submit your manuscripts at

http://www.hindawi.com
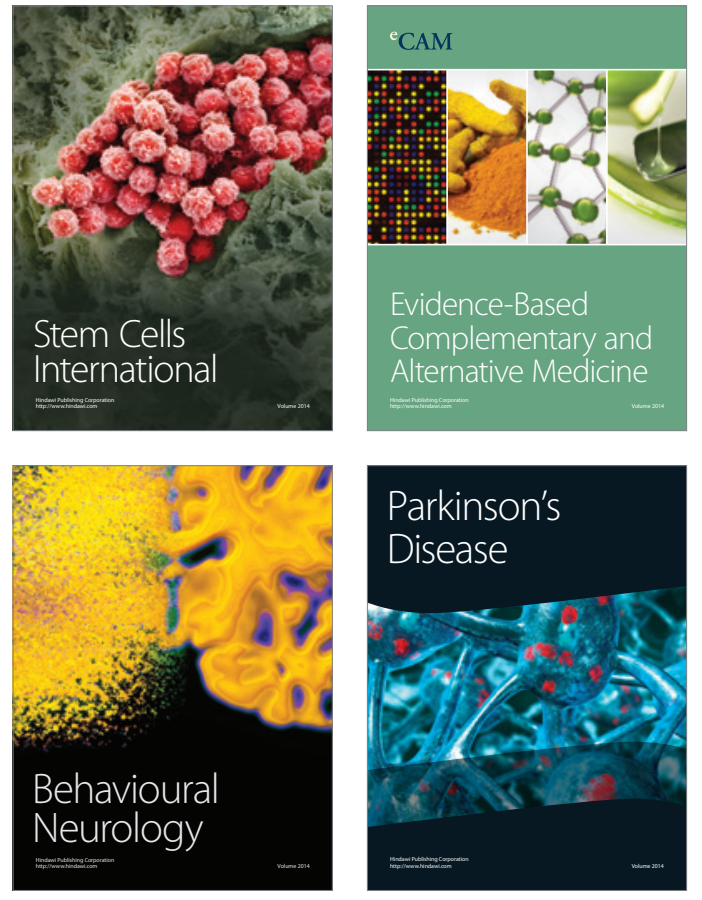
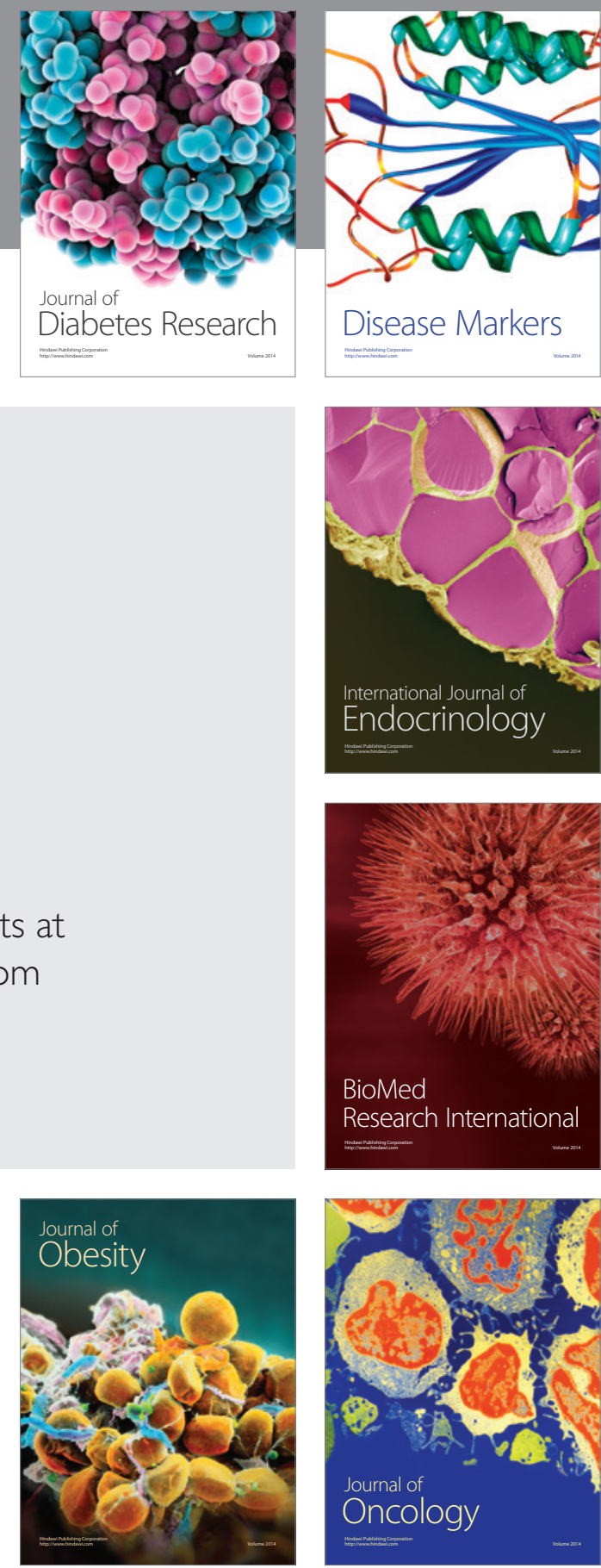

Disease Markers
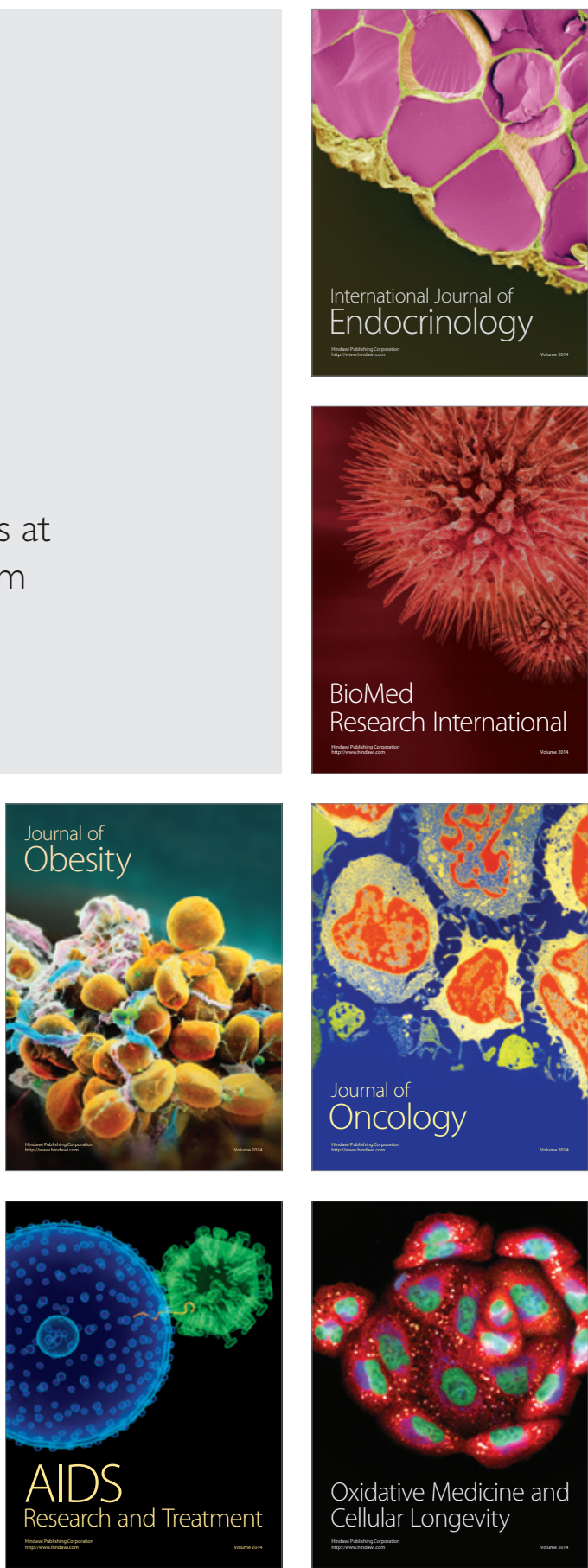